\title{
Reasonable Choices for Cytotoxic or Cytostatic Treatment in Elderly Advanced Non-Small Cell Lung Cancer Patients
}

\section{Konstantinos Zarogoulidis*}

Chair Professor of Pulmonology, Aristotle University of Thessaloniki, Director of the University pulmonary Clinic, "G. Papanikolaou" General Hospital, Greece

Nowadays, expansion of the aging population, especially in developed countries, elderly lung cancer cases show an increasing trend. Surveillance Epidemiology and End Results (SEER) program data show that patients $\geq 70$ years and older account for $47 \%$ of all lung cancer [1]. According to National Institute on Aging (NIA) and NCI SEER Collaborative Study on Comorbidity and Cancer in the Elderly, in the USA in 2030, 1 in 5 Americans will be aged $\geq 65$ years [1].

Men and women aged $\geq 65$ years have a risk and mortality of 11 and 15 times greater than persons aged $<65$ years to experience a cancer, respectively. Additionally, an elderly patient may already have concurrent health problems. Although, aging is a highly individualized process, however all the changes involved cannot be predicted safely on the basis of chronological age. In an analysis by the SEER database, about $50 \%$ of lung cancer cases diagnosed in persons aged more than 70 years, $15 \%$ of whom aged more than 80 years. The loss of organ function reserve (e.g. declining marrow and renal function) and the existence of chronic disease comorbidities (e.g. COPD, cardiac risk, use of polypharmacy etc.) lead to tolerance differences on treatment [2].

There is no agreement on the definition of "elderly" (65-7075 years?) and many believe that "biological age" rather than "chronological age" should guide medical decision. The absence of criteria and the lack of adequate laboratory tests and tools prevent the establishment of "biological age". "Chronological age" is the only indicator in defining the elderly and the age $\geq 70$ years appears as the most appropriate threshold because the incidences of age-related changes start to increase after this cut-off age. Of course calendar age is not sufficient to encompass various individuals, life style, health status, status education and social support $[3,4]$.

Limitations to the treatment of the elderly are: a) physicians and doctors hesitate to treat or treat aggressively (under-treatment), b) elderly cannot tolerate aggressive therapy, c) elderly have different wishes with respect to the prolongation of life. Socio-economic possible limitations are: the cost of treatment, the dependence on others, and the belief of relatives/doctors that "treatment is worse than the disease".

The Canadian Study of Health and Aging (CSHA) developed 7-point clinical rules based on the definition of frailty (very fit, well, well with treated comorbid disease, apparently vulnerable, mildly frail, moderately frail, severely frail) [5].

On the other hand, the Italian Association of Thoracic Oncology through an International Experts Panel Meeting with the intent to review the evidence base regarding the treatment of elderly patients with NSCLC provide instruments allowing the estimation of individual risk of mortality and treatment toxicity: the Comprehensive Geriatric Assessment (CGA) and the Chemotherapy Risk Assessment Scale for High-Age Patients Score [6].

Single-agent cytotoxic third generation monotherapies: Elderly Lung Cancer Vinorelbine Italian group Study (ELVIS) (1999), randomly assigned 154 patients to vinorelbine $30 \mathrm{mg} / \mathrm{m} 2(\mathrm{~d} 1, \mathrm{~d} 8)$ vs BSC. Vinorelbine improved Overall Survival (OS) $(\mathrm{p}=0.03)$ and QoL. In the WJT06 (2006) randomised phase III trial, 180 patients administered docetaxel at $60 \mathrm{mg} / \mathrm{m}^{2}$ every 21 days or vinorelbine 25 $\mathrm{mg} / \mathrm{m}^{2}$ (d1, d8). Docetaxel improved Progression Free Survival (PFS) $(\mathrm{p}<0.001)$ and $\mathrm{RR}(\mathrm{p}=0.019)$ but not $\mathrm{OS}$ and was associated with grade 3-4 neutropenia. Thus docetaxel considered as a reasonable agent for monotherapy in the elderly [6].

Monotherapy vs. doublets treatment: In the Multicenter Italian Lung cancer in the Elderly Study (MILES) (2003) phase III trial including 698 patients compared either vinorelbine $30 \mathrm{mg} / \mathrm{m}^{2}$ (d1, $\mathrm{d} 8$ ) or gemcitabine $\left(1200 \mathrm{mg} / \mathrm{m}^{2}, \mathrm{~d} 1, \mathrm{~d} 8\right)$ to a vinorelbine/gemcitabine doublet. Overall Survival was similar among arms but combination regimen was more toxic [6].

Single agent vs. platinum-based doublet: The GALGB 9730 phase III randomised trial compared paclitaxel $v s$. combination paclitaxel + carboplatin in elderly advanced NSCLC patients. The results showed an improvement in Response Rate (RR) and PFS when treated with the combination [7]. Outcomes regarding RR, PFS and OS from a number of phase III retrospective age-specific subgroup analyses showed no significant differences between age groups [8]. On the other hand, a high incidence of toxicity (grade $\geq 3$ ) in elderly patients was reported. In the Hellenic Oncology Research Group pooled analysis, elderly patients with NSCLC, were treated with front-line docetaxel/ gemcitabine. Chemotherapy was well tolerated but the incidence of grade 3-4 mucositis and diarrhea was significantly higher in elderly patients compared to younger patients. Multivariate analysis revealed that PS $(p=0.0001)$ and Stage $(p=0.0001)$ but not the age were significant independent factors in the hazard of death [9].

In the IFCT-0501 phase III Study 451 patients with advanced NSCLC, PS 0-2, randomized to receive weekly paclitaxel combined with monthly carboplatin vs single agent therapy (vinorelbine or gemcitabine). The combination produced better OS compared with single - agent with the cost of increased toxicity (especially neutropenia). Patients in both arms received erlotinib at the Time of Progression [10].

Nab-paclitaxel alone chemotherapy showed beneficial results as far as median OS is concerned with manageable toxicities [11].

Targeted therapies: All available evidence showed that TKIs are well tolerated compared with platinum-based chemotherapy.

Elderly patients with advanced non-squamous NSCLC should be tested for EGFR mutation and ALK rearrangement for ALK positive $[9,12]$.

*Corresponding author: Konstantinos Zarogoulidis, Chair Professor of Pulmonology Aristotle University of Thessaloniki, Director of the University pulmonary Clinic, "G. Papanikolaou" General Hospital, Greece, Tel: +3023130307251; Fax: +302310992424; E-mail: zarog@med.auth.gr

Received September 25, 2015; Accepted September 28, 2015; Published October 05, 2015

Citation: Zarogoulidis K (2015) Reasonable Choices for Cytotoxic or Cytostatic Treatment in Elderly Advanced Non-Small Cell Lung Cancer Patients. Lung Dis Treat 1: e102. doi:10.4172/ldt.1000e102

Copyright: ( 2015 Zarogoulidis K. This is an open-access article distributed under the terms of the Creative Commons Attribution License, which permits unrestricted use, distribution, and reproduction in any medium, provided the original author and source are credited. 
The addition of bevacizumab in the paclitaxel/carboplatin doublet in the elderly population did not result in a significant prolongation of median OS. On the other hand, the addition of bevacizumab resulted in significantly higher grade $\geq 3$ toxic effects compared with the paclitaxel/ carboplatin doublet [6].

\section{Conclusions}

The elderly patients are a specific population where data from younger population cannot be applied. Specifically designed clinical trials with adequate CGA are needed. Single third generation agent is a reasonable choice.

Platinum-based regimen with attenuated dose or weekly schedule could be considered for good PS elderly patients without significant comorbidities. Age, PS and Stage influence survival but PS and the extent of the disease is of greater importance.

Biological agents are well tolerated and they have to be considered as first choice for EGFR-mutated patients or with ALK positive patients.

Other targeted therapies, i.e. bevacizumab, still require further prospective evaluations.

Tailored treatment is required in many cases according to age, comorbidities and health function.

\section{References}

1. Maione P, Rossi A, Sacco PC, Bareschino MA, Schettino C, et al. (2010) Treating advanced non-small cell lung cancer in the elderly. Ther Adv Med Oncol 2: 251-260.

2. Yancik R (1997) Cancer burden in the aged: an epidemiologic and demographic overview. Cancer 80: 1273-1283.

3. Asmis TR, Seymour LDK, Shepherd FA, Leighl NB, Winton TL, et al. (2008) Age and Comorbidity As Independent Prognostic Factors in the Treatment of Non-Small-Cell Lung Cancer: A Review of National Cancer Institute of Canada Clinical Trials Group Trials. J Clin Oncol 26: 54-59.
4. Koyi H, Hillerdal G, Andersson O, Kolbeck KG, Liv P, et al. (2015) Chemotherapy Treatment of Elderly Patients ( $\geq 70$ Years) with Non-Small Cell Lung Cancer: A Seven-Year Retrospective Study of Real-Life Clinical Practice at Karolinska University Hospital, Sweden. Lung Cancer Int 2015: 317868.

5. Rockwood K, Song X, MacKnight C, Bergman H, Hogan DB, et al. (2005) A global clinical measure of fitness and frailty in elderly people. CMAJ 173: 489-495.

6. Gridelli C, Balducci L, Ciardiello F, Di Maio M, Felip E, et al. (2015) Treatment of Elderly Patients With Non-Small-Cell Lung Cancer: Results of an International Expert Panel Meeting of the Italian Association of Thoracic Oncology. Clin Lung Cancer 16: 325-333.

7. Lilenbaum RC, Herndon JE, List M, Desch C, Watson DM, et al. (2005) Single-Agent versus combination chemotherapy in advanced non-small-cell lung cancer: a CALGB randomised trial of efficacy, quality of life and cost effectiveness. J Clin Oncol 23: 190-196.

8. Pallis AG, Gridelli C, van Meerbeeck JP, Greillier L, Wedding U, et al. (2010) EORTC Elderly Task Force and Lung Cancer Group and International Society for Geriatric Oncology (SIOG) experts' opinion for the treatment of non-smallcell lung cancer in an elderly population. Ann Oncol 21: 692-706.

9. Pallis AG, Polyzos A, Boukovinas I, Agelidou A, Lamvakas L, et al. (2008) Pooled analysis of elderly patients with non-small cell lung cancer treated with front line docetaxel/gemcitabine regimen: the Hellenic Oncology Research Group experience. J Thorac Oncol 3: 505-510.

10. Quoix E, Zalcman G, Oster JP, Westeel V, Pichon E, et al. (2011) Carboplatin and weekly paclitaxel doublet chemotherapy compared with monotherapy in elderly patients with advanced non-small-cell lung cancer: IFCT-0501 randomised, phase 3 trial. The Lancet 378: 1079-1088

11. Chen H, Huang X, Wang S, Zheng X, Lin J, et al. (2015) Nab-paclitaxel (abraxane)-based chemotherapy to treat elderly patients with advanced nonsmall-cell lung cancer: a single center, randomised and open-label clinical trial. Chinese Journal of Cancer Research 27: 190-196

12. TM Jackman DM, Yeap BY, Linderman NI, Fidias P, Rabin MS, et al. (2007) Phase II Clinical Trial of Chemotherapy-Naive Patients $\geq 70$ Years of Age Treated With Erlotinib for Advanced Non-Small-Cell Lung Cancer. J Clin Oncol 25: 760-766. 